\title{
Drug Accountability Assessment Test
}

National Cancer Institute

\section{Source}

National Cancer Institute. Drug Accountability Assessment Test. NCI Thesaurus. Code C83145.

A character or string that represents the full name of the drug accountability assessment. 